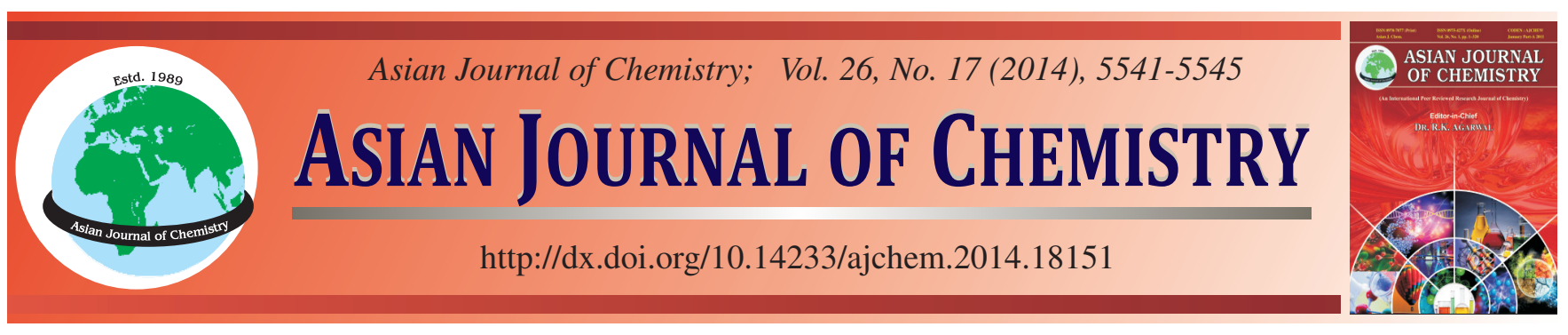

\title{
Experimental Study on Carbon Fiber Reinforced Polymer Strengthened Pre-Cracked Box Girders with Corrugated Steel Web $\dagger$
}

\author{
JiAng-Feng Dong ${ }^{1}$, Shu-Cheng Yuan ${ }^{1}$, Shi-Lei Yuan ${ }^{2}$ and Qing-Yuan Wang ${ }^{3, *}$
}

${ }^{1}$ School of Architecture and Environment, Sichuan University, Chengdu 610065, P.R. China

${ }^{2}$ State Key Laboratory of Hydraulics and Mountain River Engineering, Sichuan University, Chengdu 610065, P.R. China

${ }^{3}$ Department of Civil and Engineering Mechanics, Sichuan University, Chengdu, P.R. China

*Corresponding author: Tel./Fax: +86 28 85405389; E-mail: wangqy@ scu.edu.cn

\begin{abstract}
This paper presents an experimental study on carbon fiber reinforced polymer (CFRP) strengthened pre-cracked box girders with corrugated steel web subjected to bending. The research work covers the original crack and crack growth on the corrugated steel web, the influence of deflection and strain response. The results show that the flexural strength and load carrying capacity of the cracked corrugated steel box girders can be improved through the CFRP strengthening. As a result, the growth of the initial crack development is restrained efficiently. The new cracks are mainly located between the loading point and support. The ultimate failure mode is characterized as the shear failure on the bottom flange plate and the interfacial slippage between the web and the bottom flange. It is worth pointing out that the initial deflection of the strengthened corrugated steel web box girders is greater than that of the girder before strengthening. However, with the load increase, the former deflection is growing slowly until it becomes smaller than the latter, i.e., the strengthening enhances the stiffness of the box girder, at the same time the residual deformations are increased.
\end{abstract}

Keywords: Experimental study, Box girders with corrugated steel web, Pre-cracked, Strengthening.

\section{INTRODUCTION}

With the emergence of box girder with corrugated steel webs bridge, this new form of bridge has been attracting more and more attention ${ }^{1-3}$, due to its effective combination of box girder, external pre-stressing and the advantages of composite structure $^{4}$. As traditional concrete box girder bridges have been constructed with web reinforcing bar constraints, it is difficult to reduce their concrete thickness and further to reduce the related structural weights ${ }^{5}$. However, bridges made with box girder with corrugated steel webs have a beautiful shape and high vibration resistance ${ }^{6-8}$. In recent years, such bridges have obtained a very good promotion and development in China.

Box girders with corrugated steel web are through the pre-stressing to restrain the cracking down on cracks in the process of service. However, in the long term fatigue load or some special situation, such as seismic action, cracks in the concrete slab of box girder are hard to avoid. Carbon fiber reinforced polymer reinforcement is introduced to strengthen concrete members, with a number of research papers ${ }^{9-13}$. This high efficient reinforcement method is suitable for rapid and reliable strengthening for the damaged of structures due to accidents. Good fatigue resistance and corrosion resistant performance of CFRP makes it better to be used for the reinforcement of box girders with corrugated steel $\mathrm{web}^{14}$.

The research of box girders with corrugated steel web has been undertaken excessively. However, the research on its cracking during post-processing is limited up to date. The study covers the initial fracture development, cracking of box girders with corrugated steel web, bearing capacity, the deflection and stress response of CFRP reinforced box girder with corrugated steel webs. The results show that box girders with corrugated steel web strengthened with carbon fiber composite materials is feasible and effective.

\section{EXPERIMENTAL}

Ordinary portland cement with a 28 days compressive strength of $42.5 \mathrm{MPa}$ was used to produce specimens. River sand with the maximum size of $2.36 \mathrm{~mm}$ was used as the fine natural aggregate. The coarse aggregates have the fraction size, 4/16 mm (1), 16/27 mm (2) and 27/32 mm (3), in accordance with the Chinese standard GB/T 14685-2001. Concrete compressive strength at 28 days is $54.5 \mathrm{MPa}$. The steel grade

$†$ Presented at 2014 Global Conference on Polymer and Composite Materials (PCM2014) held on 27-29 May 2014, Ningbo, P.R. China 
of Q345qC used for the construction of the corrugated steel web, the average yield strength is $420 \mathrm{MPa}$ and the ultimate strength is $570 \mathrm{MPa}$, together with the modulus of elasticity is $201 \mathrm{GPa}$ and the Poisson's ratio is 0.3.

The strengthening material of CFRP sheets supplied by the Shanghai Keep Strong in Building Technology Engineering Co. Ltd., which have a nominal thickness of $0.11 \mathrm{~mm}$ per ply, were externally bonded onto the bottom concrete surface of box girder with corrugated steel web by using a two-part epoxy mixed in a weight ratio of $2: 1$ and then cured at room temperature. The tensile strength, elastic modulus and ultimate elongation of the CFRP sheets applied are $4103 \mathrm{MPa}, 242$ GPa and $1.7 \%$, respectively.

Specimen preparations: A specimen of box girder with corrugated steel web was designed with a length of $1600 \mathrm{~mm}$, height of $355 \mathrm{~mm}$ and span of $1400 \mathrm{~mm}$. The width of the top slab is $520 \mathrm{~mm}$ and a thickness is $45 \mathrm{~mm}$, whilst the counterpart dimensions for the base slab are 330 and $60 \mathrm{~mm}$, respectively. The top and base slabs of concrete were reinforced by HPB235 steel bar of $6 \mathrm{~mm}$ in diameter. The height of the web is $213 \mathrm{~mm}$. The width of the flange is $42 \mathrm{~mm}$, with a thickness of $2 \mathrm{~mm}$. The inter-space of perfobond leiste (PBL) shear connectors is $26.54 \mathrm{~mm}$. The heights of the shear connectors on the top and bottom are 16 and $13 \mathrm{~mm}$, respectively. Dimensions of the specimens are shown in Fig. 1.

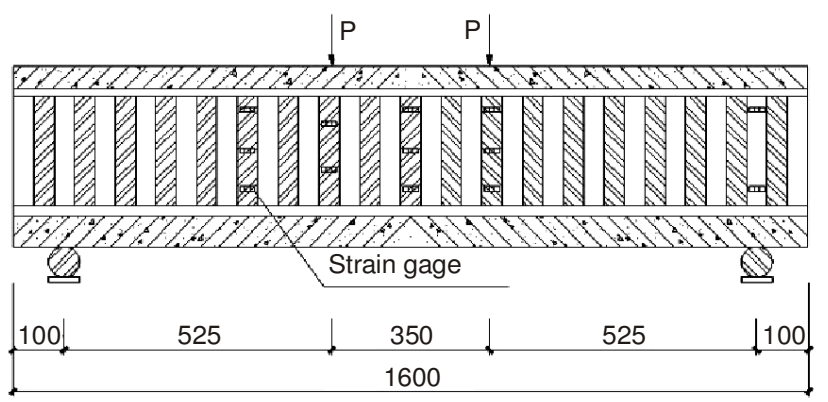

(a) Box girder elevation drawing

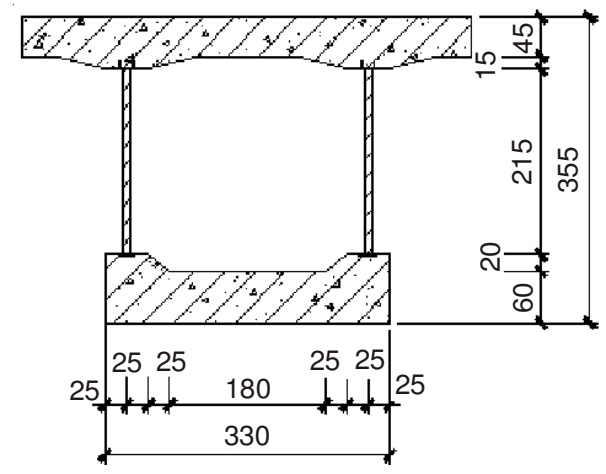

(b) Box girder viewed from the side

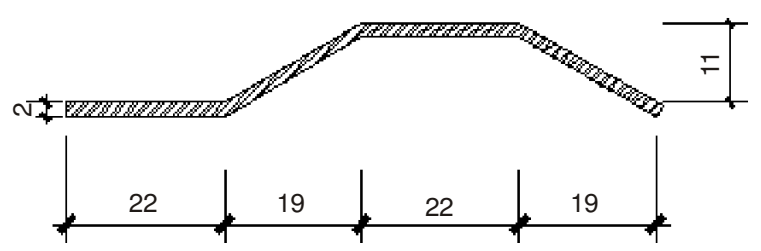

(c) Steel web plate size

Fig. 1. Details of box girders with corrugated steel web
Arrangement of strain gauges: The strain gauges were used to obtain the local deformation of the corrugated steel web during the four-point flexural bending loading before and after cracking when strengthening with CFRP. The details arrangements of strain gauges were shown in in Figs. 1(a) and 2. Moreover, three linear variable displacement transducers (LVDTs) were placed to measure the deflections corresponding to loading points and the mid-span, which is shown in Fig. 3. For the CFRP strengthened box girder, these strain gauges were fixed to the outermost layer of CFRP sheets, as shown in Fig. 2(b).



(a) Strain gauge sketch map before cracking

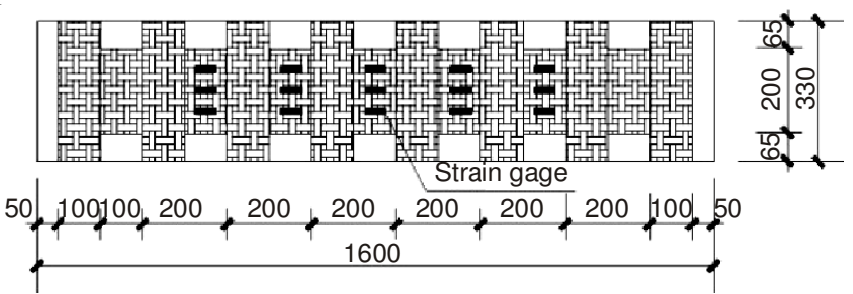

(b) Strain gauge sketch map after cracking

Fig. 2. Strain gauges arrangement of box girder tested

Test setup and procedures: The specimen of box girder is subjected to four-point bending with a cyclic loading cycle. The span of the pure bending section is $350 \mathrm{~mm}$. Details of loading schematic diagram and the cyclic loading steps are shown in Fig. 3, where the $\mathrm{P}_{\min }$ is equal to $30 \mathrm{kN}$ and the $\mathrm{P}_{\max }$ is $120 \mathrm{kN}$. The loading for each level is set to $5 \mathrm{kN}$, with a loading duration of 3 min to allow the instrument to record the displacement and the corresponding strain readings stably. The loading speed is $0.2 \mathrm{kN} / \mathrm{min}$.

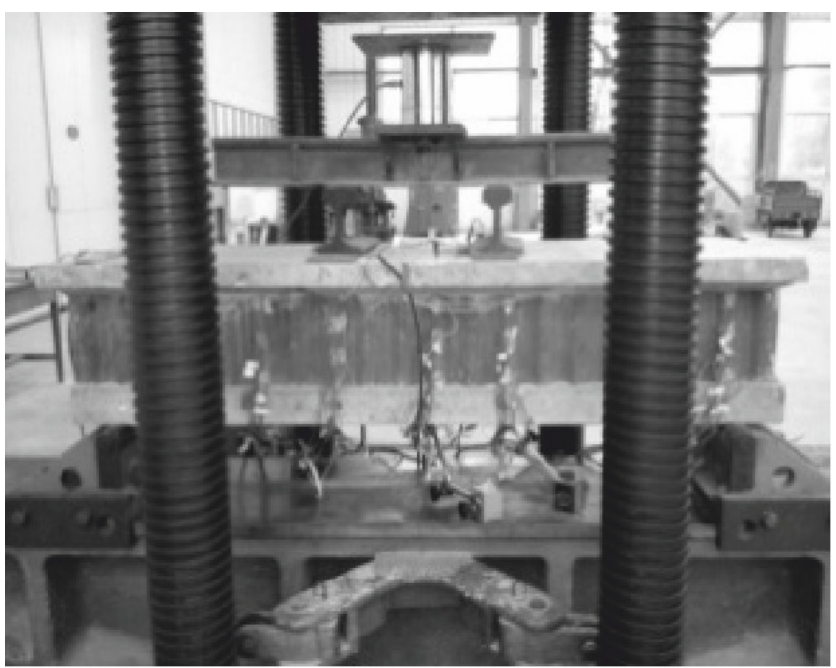

(a) Schematic view of specimen 


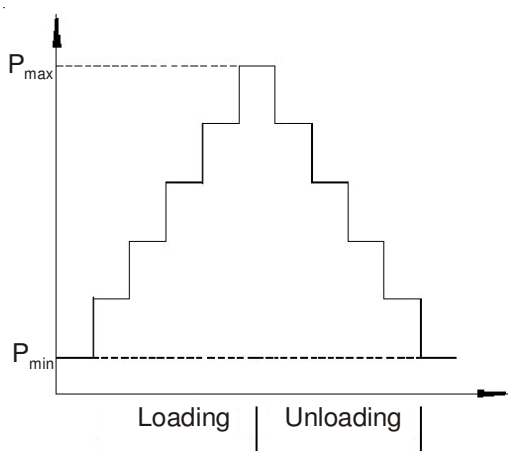

(b) Details of loading procedure

Fig. 3. Test setup and loading procedure

\section{RESULTS AND DISCUSSION}

Test phenomenon: The first cracks were appeared at the lower concrete surface beneath the loading points before strengthened with CFRP and the maximum crack length was less than $20 \mathrm{~mm}$. Then the cracks began to appear at the joint of the web plate and tensile face concrete along with the load increasing and also the cracks propagated greatly. When the load increasing up to $100 \mathrm{kN}$, the number of cracks was no longer increased and the cracks growth rate was slow down. When the load reached $120 \mathrm{kN}$, the number of cracks had reached 19. Meanwhile, two flexural cracks appeared on the bottom surface at the pure bending section with a width of $2.54 \mathrm{~mm}$, as shown in Fig. 4.

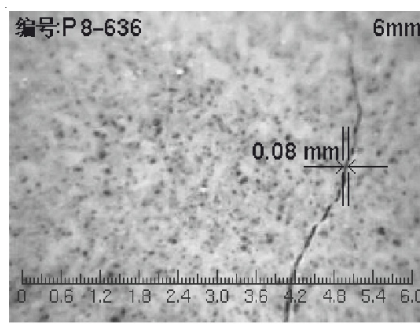

(a) Initial crack width

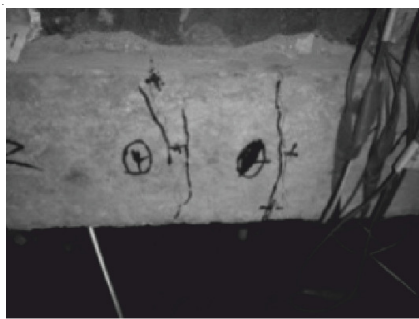

(c) Cracks at the mid-span

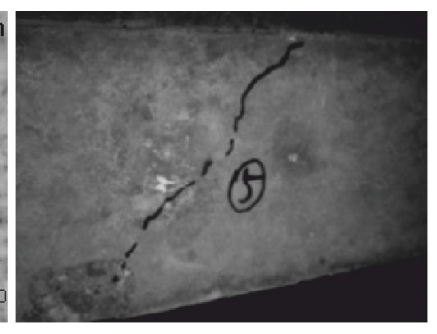

(b) Cracks at support

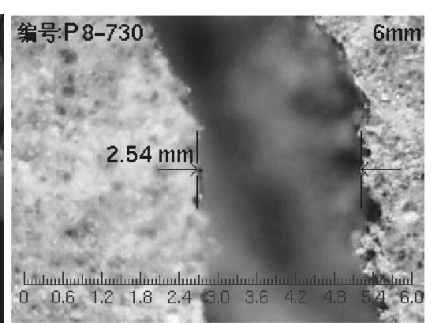

(d) Crack width at failure
Fig. 4. Cracks developed before strengthening

When the specimen strengthened with CFRP and was loaded to $110 \mathrm{kN}$, the popping sound was heard from debonding of the CFRP sheets from the concrete. As the result, the load was plunged to $107.3 \mathrm{kN}$. Then the load increased continuously, accompanied by the growing of crack width. However, the number of cracks did not change. When the load increased to $220 \mathrm{kN}$, there were new cracks appeared on the top slab. The cracks near two supports were growing in both the width and length on the tensile slab. Until the load reaching up to $275 \mathrm{kN}$, the growing rate of the displacement on the box girder was accelerated and the cracks near supports developed rapidly toward the top slab. Movement appeared in the joint of box girder plate and web plate and then the concrete near supports crushed. The maximum crack width at mid-span ultimately reached $5 \mathrm{~mm}$ and the box girder finally failed, as shown in Fig. 5.

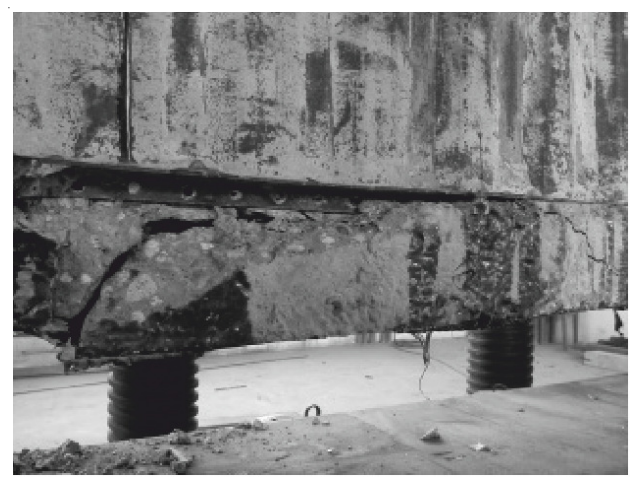

Fig. 5. Failure mode of box girder after reinforcing of CFRP

Load-deflection response: When the load was less than $80 \mathrm{kN}$, the load versus deflection curve at mid-span could be simplified into trilinear model before the box girder was reinforced. When the load reached between $80-90 \mathrm{kN}$, the stiffness had a slight reduction. It can be seen that the plastic deformation of the box girder at $120 \mathrm{kN}$ was greater than the ones at $100 \mathrm{kN}$, as many cracks were generated on the tensile slab. And also the deflection at load points was less than that of at the mid-span, as expected (Fig. 6).
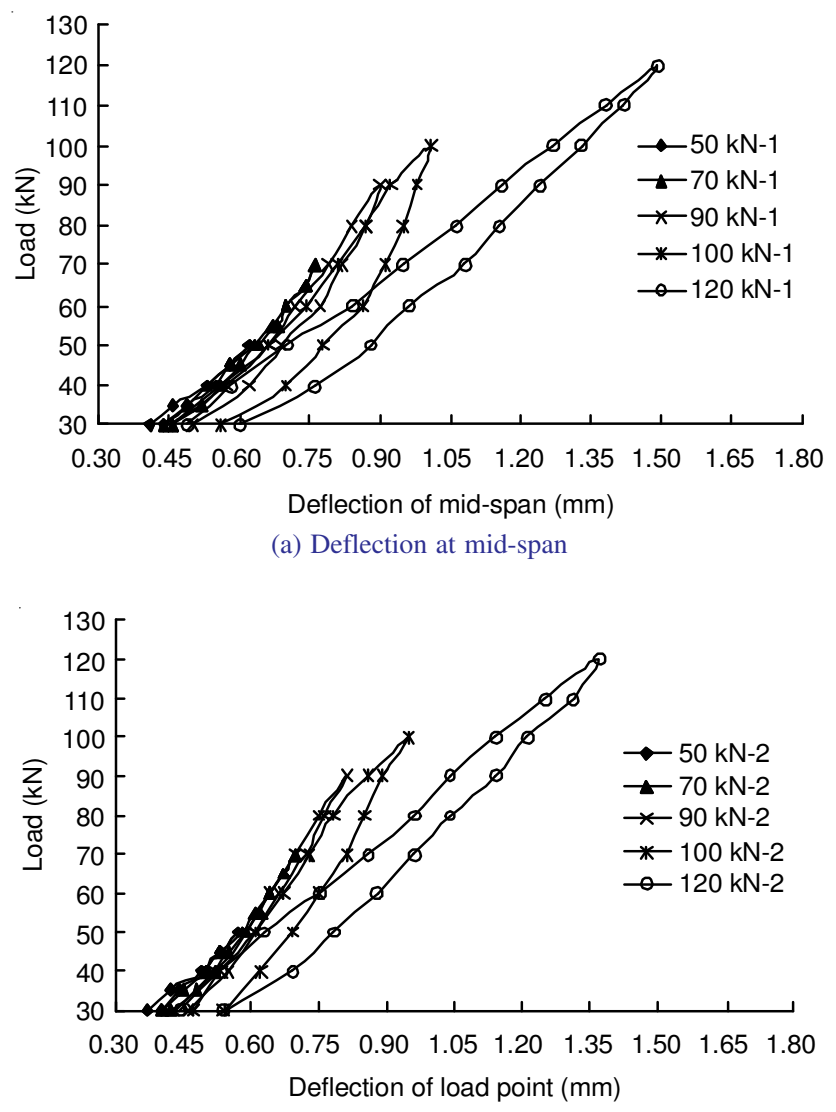

(b) Deflection at load point

Fig. 6. Load-deflection curves for box girder before reinforcing 
After the box girder is reinforced, the load-deflection curve still can be simplified into trilinear model, as shown in Fig. 7. Compared with load-deflection curves before strengthening, those curves corresponding to the CFRP strengthened box girder was smoother and the area under the curve was larger, which indicated the permanent deformations increased after unloading. These results can be attributed to the CFRP reinforcement that increases the energy dissipation by giving a large plastic deformation. The ultimate load carrying capacity of box girder with CFRP reinforcement has been significantly improved, with the increase of $17 \%{ }^{5}$.

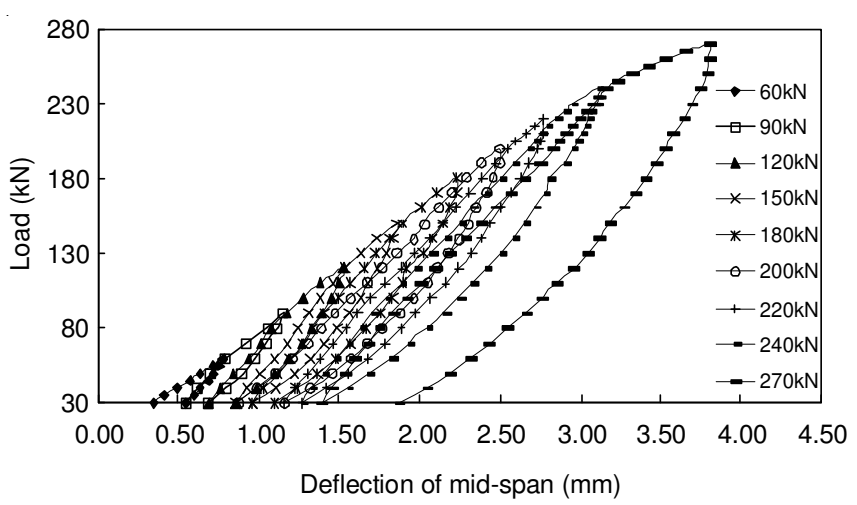

(a) Deflection at mid-span

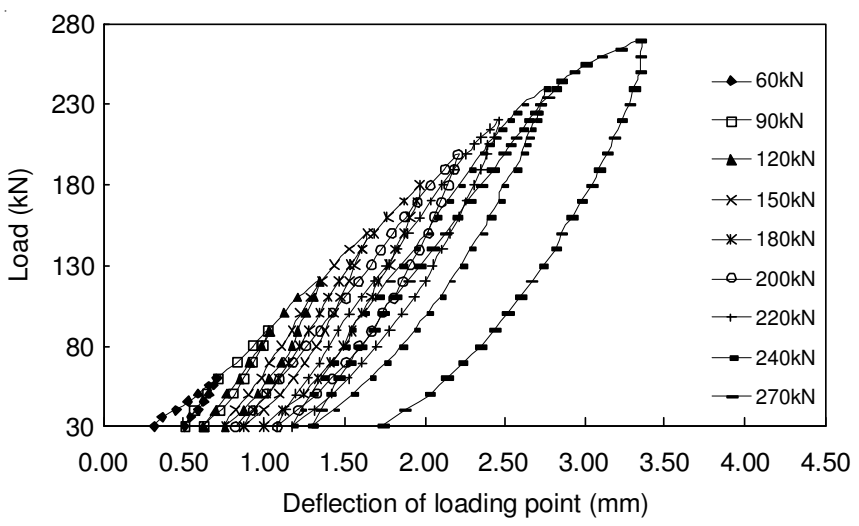

(b) Deflection at load point

Fig. 7. Load-deflection curves of box girder after strengthening with CFRP

Load-strain response: Load versus strain curves of the concrete slab show a linear feature in elastic stage before box girder was reinforced, as shown Fig. 8(a). The strains for the top concrete slab of box girder are labeled as letter T and B represent the strains on the bottom slab in Fig. 8. It can be seen that the concrete gradually lost its loading carrying capacity after the box girder cracked. For the loading at 100 and $120 \mathrm{kN}$, the strains response curves shown that the box girder still worked in the elastic stage, as shown in Fig. 8(b).

The envelope surface area of the load-strain curve increase when the box girder strengthened with CFRP. The similar phenomenon is also found from the load-deflection curves. The result suggests that the dissipation of energy of the box girder with corrugated steel web strengthened with CFRP is improved. Load-strain curves for the bottom slab are shown in Fig. 9, which showed that the strains on concrete and CFRP are almost unanimously. The results indicated that the interface between the carbon fiber and the concrete does not have any slip.

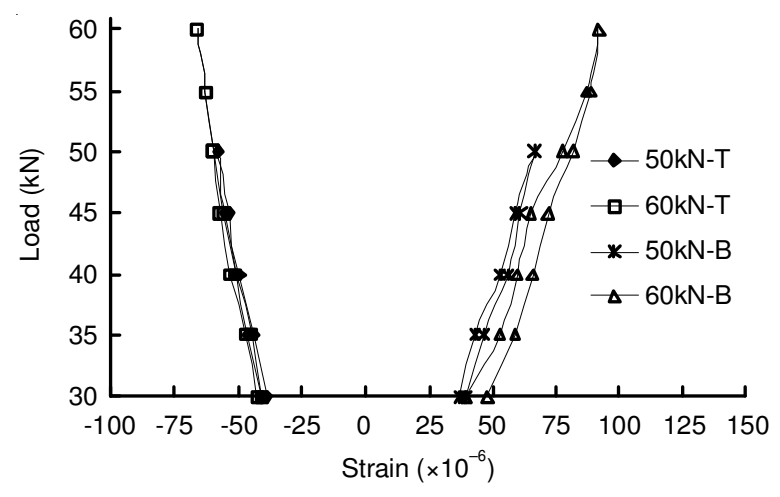

(a) Before cracking

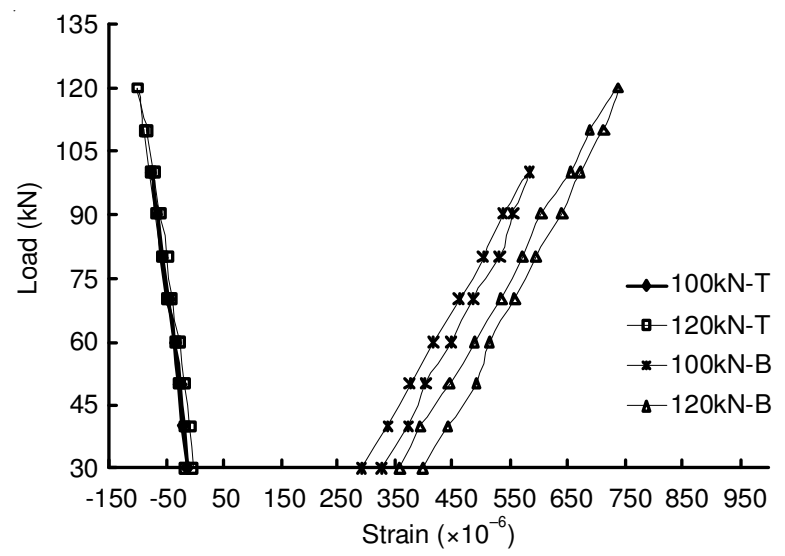

(b) After cracking

Fig. 8. Load versus strain curves of box girder

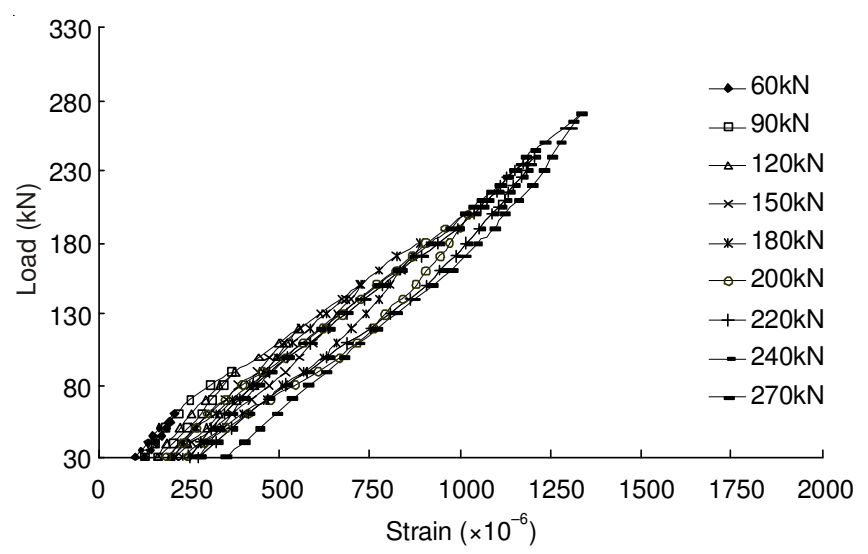

(a) Strains on concrete

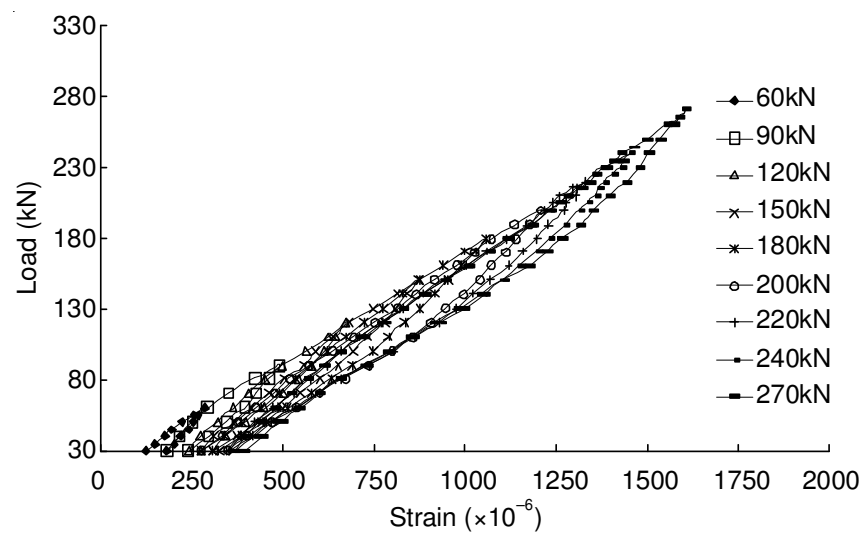

(b) Strains on CFRP

Fig. 9. Load versus strain curves for box girder reinforced 


\section{Conclusion}

This paper presents an experimental study on CFRP-strengthened pre-cracked corrugated box girders with corrugated steel web subjected to bending. The conclusions may be drawn as follows:

(1) The flexural bearing capacity of CFRP-strengthened pre-cracked box girders with corrugated steel web can be improved.

(2) Cracks on concrete plate could be restrained effectively after box girder was reinforced by CFRP.

(3) The energy absorption of pre-cracked box girders with corrugated steel web can be enhanced greatly by CFRP strengthening, along with the ductility is also improved.

\section{ACKNOWLEDGEMENTS}

The authors acknowledged the financial support provided by the Natural Science Foundation of China (No. 11327801) and the China Postdoctoral Science Foundation (Nos. 2013M542277, 2014T70870). The first author (J.-F. Dong) has been supported by the China Scholarship Council (CSC) which is greatly appreciated. The authors also thank Mr. Lang Li, Miss Min Hou, Mr. Shi-hai Dong and Miss Wei Liang for their assistance in the experi-mental work.

\section{REFERENCES}

1. H. Ren, Research on Design Theory and Experiment of Prestressed Concrete Composite Box Girder with Corrugated Steel Web, Beijing Jiaotong University, Beijing, China (2011).

2. W. Wu, S. Wan and J. Ye, China Civil Eng. J., 37, 31 (2004).

3. J.Y. Song, T. Wang and S.R. Zhang, Northeastern Highway, 25, 38 (2002).

4. X.S. Shi, Q.-Y. Wang, W.-X. Ouyang and Y.-Y. Chen, Eng. Mech., 29, 168 (2012).

5. Z.W. Peng, Department of Civil Engineering, Chengdu, Sichuan, China (2012).

6. M. Rosignoli, Struct. Build., 134, 77 (1999).

7. B.C. Chen, Q.W. Huang, Highway, 50, 45 (2005).

8. X.H. Zhou, W.W. Zhang, F.B. Wu and D.Q. Li, J. Architect. Civil Eng., 23, 54 (2006).

9. I. Jankowiak, Arch. Civil. Mech. Eng., 12, 376 (2012).

10. R. Capozucca, M. Nilde and N. Cerri, Constr. Build. Mater, 16, 91 (2002).

11. W. Wang and G. Li, Int. J. Solids. Struct., 43, 1372 (2006).

12. J. Dong, Q. Wang and Z. Guan, Composites Part B, 44, 604 (2013).

13. S. Lu, H. Xie and W. Liu, J. Shenyang. Jianzhu. Uni. (Nat. Sci.), 22, 186 (2006).

14. Y.-Y. Lu, Y.-S. Huang, H.-J. Zhang and L. Liu, China. Railway. Sci., 2, 34 (2006). 